\title{
Fourth International Conference of the African Materials Research Society Dedicated to Cementing Collaborations in Africa
}

The Fourth International Conference of the African Materials Research Society will be held December 10-14, 2007 in Dar es Salaam, Tanzania. The conference is organized by Eastern Africa-MRS in collaboration with the College of Engineering and Technology (CoET), University of Dar es Salaam, and chaired by J.V. Tesha.

The conference is aimed at "Cementing Collaborations in Materials Research in Africa" and will also provide an opportunity for MRS-Africa members to interact with other scientists and researchers from Africa and around the world as well as members of the International Conference on Nonconventional Materials (INOCMAT). The broad conference themes include

\section{www.udsm.ac.tz}

- Processing, testing, and characterization of materials, nondestructive testing;

- Infrastructure materials;

- Materials for energy production

- Composites, polymers, glasses, ceramic, metals, alloys, and oxides;

- Raw materials beneficiation and mineral processing;

- Materials recycling;

- Materials for acoustics;

- Nanomaterials;

- Biomaterials;

- Computational aspects of materials;

- Materials education;

- Materials for water treatments;

- Materials for environmental applications;
- Materials for medical application;

- Catalytic, electrical, magnetic, mechanical, optical, and thermal properties of materials;

- Nonconventional materials; and

- Materials chemistry.

The abstract deadline is June 30, 2007.

For more information, contact J.V. Tesha, President, MRS-Africa 2006-2007, Department of Engineering Materials, Faculty of Mechanical and Chemical Engineering, College of Engineering and Technology (CoET), University of Dar es Salaam, P.O. Box 35131, Dar es Salaam, Tanzania; tel. 255-2410367; fax 255-2410114; and e-mail tesha@udsm.ac.tz.

\section{Fin International Conference of Nifipide Semiconductors}

September 16-21, 2007 • MGM Grand Hotel • Las Vegas, Nevada, USA

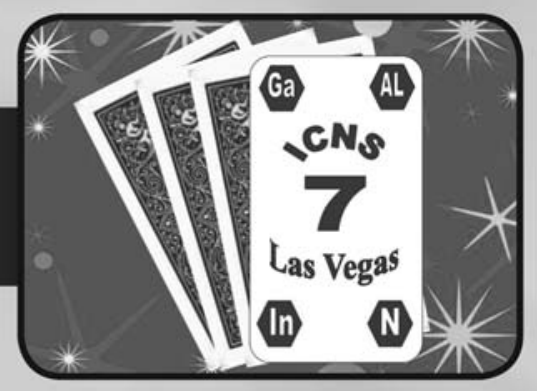

Plan to attend this biennial conference covering all aspects of Group III Nitride Semiconductors.

\section{Technical Program Emphasis:}

- Epitaxial Growth (MBE, MOVPE, HVPE, etc.)

- Bulk Crystals

- Theory

- Materials Issues (III-V-N, InN, etc.)

- Defect Engineering

- Structural Analysis

- Optical Characterization

- Nanostructures

- Devices (LEDs, laser-diodes, transistors, sensors)
For More Details

Web: www.tms.org/meetings/

specialty/icns7

E-mail: mtgserv@tms.org

Telephone: (724) 776-9000, ext. 243

(800) 759-4TMS

Sponsored by

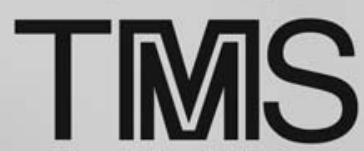

